\title{
INFLUÊNCIA DA INGESTÃO DE BIOMASSAS DE SPIRULINA (Arthrospira sp.) SOBRE O PESO CORPORAL E CONSUMO DE RAÇÃO EM RATOS ${ }^{1}$
}

\author{
Kátia Gomes de Lima ARAÚJO ${ }^{2, *}$, André Dumont FACCHINETTI² ${ }^{2}$ César Pereira dos SANTOS ${ }^{3}$
}

\begin{abstract}
RESUMO
Neste trabalho verificou-se a influência do consumo de biomassas provenientes de três diferentes origens sobre o peso corporal e consumo de ração em ratos Wistar, machos e adultos. Grupos que consumiram $5 \%$ ou $10 \%$ (p/p) da biomassa foram comparados com um controle. A biomassa I não promoveu diferença significativa no consumo de ração ou peso corporal dos três grupos. A biomassa II não causou diferença significativa no peso corporal, mas sim no consumo de ração. A biomassa III não causou diferença significativa no consumo de ração, nem no peso corporal, mas houve tendência de maior ganho de peso para o grupo que consumiu a ração contendo $10 \%$ de spirulina. Os resultados obtidos indicam que diferentes biomassas podem apresentar diferentes propriedades, mas não confirmam a alegação de que a spirulina pode levar a diminuição de peso ou de consumo de alimento.

Palavras-chave: Biomassa de spirulina; peso corporal; dieta de emagrecimento.
\end{abstract}

\section{SUMMARY}

INFLUENCE OF CONSUMPTION OF SPIRULINA (Arthrospira sp.) BIOMASSES ON BODY WEIGHT AND FOOD INTAKE IN RATS. In this work, it was verified the influence of the consumption of biomass from different origins on the body weight gain and food consumption by adult male Wistar rats. Groups fed the biomasses in the levels of $5 \%$ or $10 \%(\mathrm{w} / \mathrm{w})$ were compared with a control. Biomass I did not promote significant differences in food consumption or body weight. Biomass II did not cause significant difference in the body weight, but it caused an increase in food consumption. Biomass III did not cause significant differences in food consumption or body weight, but there was a tendency of increasing body weight for the $10 \%$ spirulina group. The hypothesis that different biomasses may have different properties was confirmed, but not the claim that spirulina may decrease body weight or food consumption.

Keywords: Spirulina biomass; body weight; slimming diet.

\section{1 - INTRODUÇÃO}

O gênero Arthrospira (ordem Oscillatoriales) contém o grupo de cianobactérias filamentosas caracterizadas por uma cadeia de células na forma de espiral e envolvida por uma bainha fina, cujas paredes transversas podem ser vistas sob microscopia ótica [6]. Embora o gênero Arthrospira tenha sido oficialmente incluido no Bergey's Manual of Systematic Bacteriology em 1989 [5], as espécies Arthrospira maxima e Arthrospira platensis, que são cultivadas em nivel industrial em diversas regiões do mundo, são freqüentemente referidas como Spirurilina maxima e Spirulina platensis, e a biomassa destas cianobactérias é comercializada com a denominação de 'spirulina'. Esta denominação é ainda uma influência do tratado taxonômico publicado por Geitler em 1932, que propôs que todas as espécies da ordem Oscillatoriales que formam filamentos helicoidais fossem incluídas no gênero Spirulina. Entretanto, em 1892 os gêneros Arthrospira e Spirulina (cujas dimensões do filamento são bem menores) já haviam sido separados por Gomont, que foi citado por GUGLIELMI et al. [6]. Atualmente, o posicionamento de Arthrospira e Spirulina em dois gêneros separados é adotado por diversos autores $[6,9,10] \mathrm{e}$

1. Recebido para publicação em 27/07/1999. Aceito para publicação em 07/06/2002.

2. UNIVERSIDADE FEDERAL FLUMINENSE - Faculdade de Farmácia -

Departamento de Bromatologia - Rua Mário Viana, 523 - Niterói - CEP

24241-000 - RJ. E-mail: klima@vm.uff.br.

3. UNIVERSIDADE FEDERAL DO RIO DE JANEIRO - Instituto de Química

- Departamento de Bioquímica - Rio de Janeiro - CEP 21949-900 - RJ.

E-mail: cesar@iq.ufrj.br.

* A quem a correspondência deve ser enviada. a separação entre os dois gêneros tem sido confirmada repetidamente com base em muitas caracteristicas morfológicas e genéticas [11]. Mas mesmo assim a denominação spirulina tem sido usada para designar a biomassa das cianobactérias do gênero Arthospira, que é comercializada como suplemento alimentar para animais e seres humanos.

$\mathrm{Na}$ atualidade, cerca de vinte e duas companhias no mundo produzem biomassa de spirulina, e o principal destino de seus produtos são lojas de produtos naturais e farmácias, onde a biomassa seca é vendida como suplemento alimentar, além da alimentação animal e extração de pigmentos para uso em alimentos no Japão [3].

Considerável atenção tem sido dada ao conteúdo de certos nutrientes na biomassa desta cianobactéria, principalmente no que se refere à proteína, vitaminas e lipídeos. Ultimamente, interesse tem surgido em relação às propriedades farmacológicas de substâncias presentes na biomassa de spirulina, como o ácido $\gamma$-linolênico e polissacarídeos. Em trabalho de revisão publicado em 1993 [4], são citados vários estudos cujos resultados indicam um grande potencial para o uso farmacológico desta cianobactéria. São citados efeitos na estimulação do sistema imunológico e da microbiota intestinal, contra hiperlipidemia, hipercolesterolemia, tumor bucal, hipertensão, efeitos tóxicos de radiações, obesidade e diabetes, atribuindo a esta cianobactéria um conjunto de propriedades que dificilmente podem ser encontradas concomitantemente em um único produto natural. Em virtude destes possíveis efeitos, a biomassa de spirulina foi apontada como sendo de grande interesse para a pesquisa de moléculas bioativas. 
Apesar da biomassa de spirulina ser indicada como auxiliar em dietas que requerem diminuição da ingestão calórica, por conter substâncias que parecem prolongar o tempo de trânsito gástrico e produzir sensação de saciedade [7], somente o trabalho de BECKER et al. [2] descreve um experimento com humanos com o objetivo de estabelecer uma relação entre o consumo desta biomassa e a diminuição do peso corporal. No trabalho citado, foi observada uma discreta redução no peso corporal de indivíduos que consumiram tabletes contendo spirulina, entretanto, as curvas de peso corporal dos grupos experimental e controle não apresentaram diferença estatisticamente significante entre si.

Todavia, esta biomassa é comercializada sem que sejam consideradas as condições de cultivo nem a espécie de cianobactéria. É possível que fatores como intensidade de luz, temperatura e composição do meio de cultivo, que podem variar de uma região produtora para outra, além do estágio de crescimento celular, possam resultar no acúmulo de diferentes metabólitos, e proporcionar atividades biológicas distintas em função de tais condições.

O presente trabalho teve como objetivo verificar a influência da ingestão de biomassas de spirulina oriundas de três países diferentes sobre o peso corporal e consumo de ração de ratos Wistar machos e adultos.

\section{2 - MATERIAL E MÉTODOS}

\section{1 - Animais de experimentação}

Foram utilizados ratos machos adultos da linhagem Wistar provenientes do Biotério da Faculdade de Farmácia da Universidade Federal Fluminense. Os animais foram alojados individualmente em gaiolas metabólicas. A temperatura da sala de animais foi mantida entre $21^{\circ} \mathrm{e}$ $24^{\circ} \mathrm{C}$, e houve alternância automática de claro-escuro em periodos de 12 horas. A dieta e a água foram oferecidas ad libitum e o período experimental foi de vinte e oito dias, durante os quais verificou-se o peso corporal e o consumo de ração. Cada grupo foi composto de oito animais.

\section{2 - Biomassas e rações experimentais}

Os experimentos foram efetuados utilizando-se biomassas de spirulina comercializadas por revendedores de produtos farmacêuticos e naturais, cujas procedências declaradas foram México (biomassa I), China (biomassa II) e Cuba (biomassa III). Após o recebimento, as biomassas secas foram reidratadas e observadas sob microscopia ótica, na tentativa de verificação da autenticidade das mesmas. Foram formuladas rações contendo $5 \%$ e $10 \%(\mathrm{p} / \mathrm{p})$ de cada biomassa, e o efeito das rações sobre os parâmetros em estudo foi comparado com o de uma ração controle para cada bloco de experimento. A formulação das rações encontra-se na Tabela 1.

\section{3 - Análises estatísticas}

Os resultados foram submetidos a análise de variância para detecção de diferença significativa entre os gru- pos. Os dados foram analisados com o auxílio do programa Graphpad Prism versão 2.0. Valores de $P$ maiores que 0,05 foram considerados como diferença não significativa.

TABELA 1. Formulação das rações experimentais (g/100 g)

\begin{tabular}{ccc}
\hline Componente & Ração controle & Rações de spirulina \\
& & \\
\hline Biomassa de spirulina & 12,5 & 5,0 ou 10,0 \\
Proteína* & 8,0 & q.s.p. 12,5 \\
Óleo de soja & 4,0 & 8,0 \\
Celulose & 4,0 & 4,0 \\
Mistura salina & 1,0 & 4,0 \\
Mistura vitamínica & q.s.p. 100,0 & 1,0 \\
Amido de milho & q.s.p. 100,0 \\
\hline
\end{tabular}

* Caseina comercial, contendo $81,3 \%(\mathrm{p} / \mathrm{p})$ de proteína

\section{3 - RESULTADOS E DISCUSSÃO}

Na Tabela 2 são mostrados os resultados para algumas observações microscópicas da três biomassas, bem como para os seus conteúdos de proteína. Apesar de, após a reidratação, grande parte dos filamentos mostrarem-se fragmentados, algumas características descritas para o gênero Arthrospira [6] foram observadas nas três biomassas, como a forma do filamento frouxamente espiralada, as paredes transversas visiveis e as células terminais formando caliptras, que são células terminais em formato de ponta. As médias do diâmetro dos filamentos também concordaram com os valores descritos pelos autores citados. Cabe enfatizar que não foram observadas por microscopia ótica indicações da ocorrência de outras cianobactérias ou microalgas nas amostras das três biomassas.

TABELA 2. Algumas características das três biomassas testadas

\begin{tabular}{|c|c|c|c|}
\hline Característica analisada & Biomassa I & Biomassa II & Biomassa III \\
\hline Forma espiralada do filamento & $\mathrm{P}$ & $\mathrm{P}$ & $\mathrm{P}$ \\
\hline Paredes transversas visíveis* & $\mathrm{P}$ & $\mathrm{P}$ & $\mathrm{P}$ \\
\hline Células terminais formando caliptras & $P$ & $\mathrm{P}$ & $\mathrm{P}$ \\
\hline Diâmetro dos filamentos $(\mu \mathrm{m})^{\star *}$ & $7,85 \pm 1,10$ & $9,41 \pm 0,95$ & $8,21 \pm 1,17$ \\
\hline $\begin{array}{c}\text { Conteúdo de proteína ( } \mathrm{g} / 100 \mathrm{~g} \text { de } \\
\text { biomassa seca) }\end{array}$ & 53,8 & 58,1 & 59,7 \\
\hline
\end{tabular}


As variações de peso corporal dos ratos de acordo com as rações ingeridas e em função do tempo de experimentação encontram-se na Tabela 3. Foi possível observar que, quando foram testadas as rações contendo a biomassa I, a ingestão de spirulina não promoveu diferença significativa em relação ao seu controle para o peso corporal dos grupos testados em nenhum tempo considerado $(\mathrm{P}>0,05)$. $\mathrm{O}$ consumo de ração (Figura 1), neste caso, também não apresentou diferença significativa dentre os grupos.

TABELA 3. Peso corporal (g) de ratos em função dos dias de ingestão de rações contendo diferentes biomassas de spirulina

\begin{tabular}{|c|c|c|c|c|c|c|c|c|c|}
\hline Dias & $\mathrm{Cl}$ & B। 5\% & B। 10\% & CII & B ॥ $5 \%$ & B II 10\% & CIIII & B III 5\% & B III $10 \%$ \\
\hline 0 & $\begin{array}{c}277,2 \pm \\
33,24\end{array}$ & $\begin{array}{c}279,7 \pm \\
26,0\end{array}$ & $\begin{array}{c}279,7 \pm \\
25,5\end{array}$ & $\begin{array}{c}240,8 \pm \\
31,5\end{array}$ & $\begin{array}{c}242,1 \pm \\
10,5\end{array}$ & $\begin{array}{c}238,8 \pm \\
33,4\end{array}$ & $\begin{array}{c}251,6 \pm \\
18,8\end{array}$ & $\begin{array}{c}255,0 \pm \\
31,4\end{array}$ & $\begin{array}{c}255,2 \pm \\
23,7\end{array}$ \\
\hline 7 & $\begin{array}{c}309,7 \pm \\
31,7\end{array}$ & $\begin{array}{c}307,6 \pm \\
25,7\end{array}$ & $\begin{array}{c}309,1 \pm \\
26,8\end{array}$ & $\begin{array}{c}276,3 \pm \\
26,4\end{array}$ & $\begin{array}{c}286,4 \pm \\
13,3\end{array}$ & $\begin{array}{c}274,9 \pm \\
40,8\end{array}$ & $\begin{array}{c}290,4 \pm \\
26,9\end{array}$ & $\begin{array}{c}302,1 \pm \\
32,9\end{array}$ & $\begin{array}{c}304,5 \pm \\
26,0\end{array}$ \\
\hline 14 & $\begin{array}{c}338,3 \pm \\
37,7\end{array}$ & $\begin{array}{c}328,8 \pm \\
22,9\end{array}$ & $\begin{array}{c}334,4 \pm \\
30,8\end{array}$ & $\begin{array}{c}312,3 \pm \\
31,3\end{array}$ & $\begin{array}{c}320,1 \pm \\
21,8\end{array}$ & $\begin{array}{c}307,6 \pm \\
49,4\end{array}$ & $\begin{array}{c}317,7 \pm \\
26,3\end{array}$ & $\begin{array}{c}322,4 \pm \\
31,3\end{array}$ & $\begin{array}{c}333,1 \pm \\
28,8\end{array}$ \\
\hline 21 & $\begin{array}{c}355,1 \pm \\
37,5\end{array}$ & $\begin{array}{c}338,9 \pm \\
24,7\end{array}$ & $\begin{array}{c}346,5 \pm \\
37,4\end{array}$ & $\begin{array}{c}338,7 \pm \\
33,3\end{array}$ & $\begin{array}{c}345,4 \pm \\
16,3\end{array}$ & $\begin{array}{c}340,3 \pm \\
47,4\end{array}$ & $\begin{array}{c}338,8 \pm \\
22,7\end{array}$ & $\begin{array}{c}344,2 \pm \\
33,2\end{array}$ & $\begin{array}{c}361,7 \pm \\
31,4\end{array}$ \\
\hline 28 & $\begin{array}{c}369,6 \pm \\
35,6\end{array}$ & $\begin{array}{c}352,5 \pm \\
26,3\end{array}$ & $\begin{array}{c}359,7 \pm \\
39,4\end{array}$ & $\begin{array}{c}352,4 \pm \\
36,5\end{array}$ & $\begin{array}{c}368,5 \pm \\
22,7\end{array}$ & $\begin{array}{c}356,8 \pm \\
42,7\end{array}$ & $\begin{array}{c}359,8 \pm \\
25,5\end{array}$ & $\begin{array}{c}354,8 \pm \\
32,0\end{array}$ & $\begin{array}{c}374,4 \pm \\
33,0\end{array}$ \\
\hline
\end{tabular}

Pela Tabela 3 ficou evidente também que a biomassa II não resultou na redução do peso corporal em relação ao grupo controle em nenhum tempo considerado ( $P>0,05$, em todos os tempos testados). Entretanto, houve diferença significativa entre os grupos no que diz respeito ao consumo das rações contendo a biomassa II (Figura 1), visto que os valores de consumo alimentar dos grupos de spirulina apresentaram diferença significativa em relação ao grupo controle $(\mathrm{P}<0,05$ e $\mathrm{P}<0,001$, respectivamente, para as rações de $5 \%$ e $10 \%)$. Este resultado não confirmou a alegação de que a spirulina pode levar à diminuição da ingestão de alimento e mostrou que a biomassa II apresentou tendência de promover maior ingestão de ração pelos animais. A despeito da maior ingestão de alimento, os resultados de peso corporal para a biomassa II indicaram que, provavelmente, nos grupos de spirulina o aproveitamento do alimento não foi tão bom quanto no controle.

No experimento com a biomassa III, também não foi verificada diferença significativa no peso dos animais em nenhum tempo considerado $(\mathrm{P}>0,05)$, no entanto, pela Tabela 3, parece que houve uma maior tendência de ganho de peso para o grupo que ingeriu $10 \%$ da biomassa. Neste caso, também não houve diferença significativa entre o consumo de ração dos três grupos $(\mathrm{P}>0,05)(\mathrm{Fi}$ gura 1).

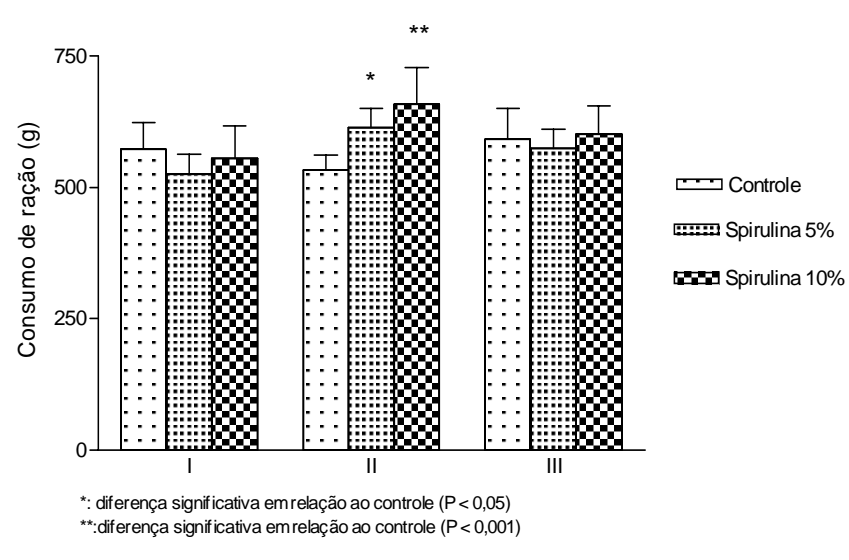

FIGURA 1. Consumo de ração dos diferentes grupos durante 28 dias em função da origem da biomassa de spirulina (I, II e III) (barras verticais $=$ desvio padrão)

A Tabela 4 mostra os resultados expressos em quociente de eficácia alimentar (ganho de peso/ração consumida (g/g)) para todos os grupos testados. Como pode ser verificado, em nenhum dos experimentos efetuados houve diferença significativa entre os grupos que consumiram as rações de biomassa e o seu respectivo controle. Mesmo no caso da biomassa II, onde ficou evidenciado maior consumo de ração nos grupos que ingeriram a biomassa, o ganho de peso por grama de ração consumida não foi diferente do controle.

TABELA 4. Ganho de peso/ração consumida (g/g) (quociente de eficácia alimentar) para as diferentes biomassas durante o período experimental

\begin{tabular}{ccccccccc}
\hline C I & B I $5 \%$ & B I 10\% & C II & B II 5\% & B II $10 \%$ & C III & B III $5 \%$ & B III 10\% \\
\hline & & & & & & & & \\
$0,16 \pm$ & $0,14 \pm$ & $0,14 \pm$ & $0,21 \pm$ & $0,20 \pm$ & $0,20 \pm$ & $0,18 \pm$ & $0,18 \pm$ & $0,20 \pm$ \\
0,01 & 0,03 & 0,04 & 0,05 & 0,02 & 0,03 & 0,04 & 0,03 & 0,03 \\
& & & & & & & \\
\hline C: Controle
\end{tabular}

C: Controle
B: Biomassa

Nos Estados Unidos da América, o FDA (Food and Drug Administration) investigou uma série de produtos cujas propagandas alegavam propriedades de redução de peso corporal sem efeitos colaterais, que poderiam representar um potencial de risco para quem consome ou apresentar apenas efeito placebo. Alguns produtos surgiram no mercado sem a aprovação do FDA, já que foram lançados como alimentos, não estando portanto sujeitos a aprovação prévia como é exigido para as drogas. Este foi o caso da spirulina, que é anunciada como alimento ou complemento alimentar, e portanto pode ser legalmente comercializada. O FDA reconhece que a spirulina é uma fonte de proteína, vitaminas e minerais, mas, nas quantidades recomendadas para consumo pelos fabricantes, os nutrientes são ingeridos em quantidades insignificantes. A propaganda enfatiza que a 
fenilalanina presente na biomassa atua no centro cerebral que controla a fome. Entretanto, o FDA fez uma revisão dos dados disponiveis sobre a fenilalanina, e não encontrou argumentos suficientes sobre a sua segurança e efetividade no controle do apetite [12].

Resultados anteriores [8] mostraram que houve diferença significativa no peso corpóreo promovida pela ingestão de spirulina por ratos somente quando o nível de biomassa na dieta foi maior que 10,7\%. Esta diminuição no peso corporal foi acompanhada de aumento significativo na matéria seca e gordura nas fezes, indicando prejuízo ao aproveitamento de alimento em função do aumento no conteúdo de biomassa na dieta.

Em geral, biomassas microbianas possuem elevados teores de ácidos nucleicos, os quais têm sido relatados como cerca de 4 - $6 \%$ para microalgas e cianobactérias, 8 $-12 \%$ para leveduras e $20 \%$ para bactérias. Devido à inabilidade do organismo humano para metabolizar o ácido úrico proveniente do metabolismo das purinas, o aumento no consumo de ácidos nucleicos pode levar a altos níveis de ácido úrico no soro. Desta forma poderia culminar com o desenvolvimento de moléstias como a gota, e por isso recomenda-se que a ingestão diária máxima de ácidos nucleicos de fontes não convencionais seja de 2,0g/ dia, com ácidos nucleicos totais não ultrapassando $4,0 \mathrm{~g} /$ dia. Como conseqüência, um limite tolerável para o consumo diário de microalgas e cianobactérias seria de $30 \mathrm{~g}$ [1], o que representaria menos de $10 \%$ do consumo diário de alimento de um adulto normal.

Os resultados obtidos com as três biomassas utilizadas neste trabalho não confirmaram a alegação de que a spirulina pode levar à diminuição de peso corporal e consumo de alimento, quando as biomassas foram adicionadas às dietas ao nível máximo de 10\%. Estes resultados foram independentes das origens das biomassas utilizadas e das possiveis diferenças de espécies da cianobactéria constituintes das três biomassas.

\section{4 - CONCLUSÕES}

Os resultados obtidos neste trabalho mostraram que o consumo de spirulina (Arthrospira sp.) por ratos, aos níveis de $5 \%$ e $10 \%$ da dieta, não levou a uma diminuição no peso corporal nem no consumo alimentar, causando mesmo às vezes um aumento neste consumo.

\section{5 - REFERÊNCIAS}

[1] BECKER, E. W. Microalgae for human and animal consumption. In: BOROWITZKA, M. A. \& BOROWITZKA, L. J. (Eds.) Microalgal Biotechnology. p: 222 - 255, Cambridge, Cambridge University Press, 1988.

[2] BECKER, E. W.; JAKOBER, B.; LUFT, D.; SCHMILLING, R. M. Clinical and biochemical evaluations of the alga Spirulina with regard to its application in the treatment of obesity. A double-blind cross-over study. Nutrition Reports International, Los Altos, v. 33, n. 4, p. $565-574,1986$.
[3] BELAY, A. Mass culture of Spirulina in outdoors - The Earthrise Farms experience. In: VONSHAK, A. (Ed.) Spirulina platensis (Arthrospira): Physiology, Cellbiology and Biotechnology. p: 131-158, London, Ed. Taylor and Francis, 1997.

[4] BELAY, A.; OTA, Y.; MIYKAWA, K.; SHIMATSU, H. Current knowledge on potential health benefits of Spirulina. J. Appl. Phycology, Dordrecht, v. 5, n. 2, p. 235 - 241, 1993.

[5] CASTENHOLZ, R. W. Subsection III, Order Oscillatoriales. In: STALEY, J. T.; BRYANT, M. P.; PFENNIG, N.; HOLT, J. G. (Eds.) Bergey's Manual of Systematic Bacteriology. v. III, p. 1771 - 1780, Baltimore, Ed. William \& Wilkins, 1989.

[6] GUGLIELMI, G.; RIPPKA, R.; TANDEAU de MARSAC, N. Main properties that justify different taxonomic positions of Spirulina spp. and Arthrospira spp. among cyanobacteria. Bulletin de 1'Institute Océanographique, Monaco, $\mathrm{n}^{\circ}$ spécial 12: 13-23, 1993.

[7] MARANESI, M.; BARZANTI, V.; CARENINI, G.; GENTILI, P. Nutritional studies on Spirulina maxima. Acta Vitamilol. Enzymol., Milano, v. 6, n. 4, p. 295 - 304, 1984.

[8] MITCHELL, G. V.; GRUNDEL, E.; JENKINS, M. ; BLAKELY, S. R. Effects of graded dietary levels of Spirulina on vitamins $A$ and $\mathrm{E}$ in male rats. J. Nutrition, Philadelphia, v. 120, n. 10 , p. 1235 - 1240, 1990.

[9] RIPPKA, R.; WATERBURRY, J. B.; STANIER, R. I. Provisional, generic assigment for cyanobacteria in pure culture. In: STARR, M.; STOLP, H.; TRUPER, H. G.; BALOWS, A.; SCHLEGEL, H. G. (Eds.) The Prokariotes, v. 1, p. 247, Berlin, Ed. Springer-Verlag, 1981.

[10] SCHELDEMAN, P.; BAURAIN, D.; BOUHY, R.; SCOTT, M.; MUHLING, M.; WHITTON, B. A.; BELAY, A.; WILMOTTE, A. Arthrospira ('Spirulina') strains from four continents are resolved into only two clusters, based on amplified ribossomal DNA restriction analysis of the internally transcribed spacer. FEMS Microbiology Letters, Amsterdam, v. 172, n. 2, p. 213 - 222, 1999.

[11] TOMASELLI, L. Morphology, ultrastructure and taxonomy. In: VONSHAK, A. (Ed.) Spirulina platensis (Arthrospira): Physiology, Cell-biology and Biotechnology. p: 1-15, London, Ed. Taylor and Francis, 1997.

[12] WILLIS, J. About body wraps, pills and other magic wands for losing weight. FDA Consumer, Washington, v. 16, U. S. Food and Drug Administration. November, 1982. 